\title{
Letter to Editor Commenting on "Patterns of Gall Bladder Wall Thickening in Dengue Fever"
}

Authors

Beuy Joob ${ }^{1}$, Viroj Wiwanitkit ${ }^{2}$

Affiliations
1 Sanitation 1 Medical Academic Center, Bangkok Thailand
2 Visiting professor, Hainan Medical University, China

received 14.06 .2017

revised 14.06.2017

accepted 12.08.2017

Bibliography

DOI https://doi.org/10.1055/s-0043-119418

Ultrasound Int Open 2017; 3: E165

(c) Georg Thieme Verlag KG Stuttgart · New York

ISSN 2199-7152

\author{
Correspondence \\ Beuy Joob \\ Sanitation 1 Medical Academic Center \\ Bangkok \\ Thailand \\ beuyjoob@hotmail.com
}

\section{Dear Editor,}

Parmar et al. reported an interesting finding in "Patterns of Gall Bladder Wall Thickening in Dengue Fever" and implied a relationship with the severity of dengue [1]. Parmar et al. noted that "the uniform echogenic pattern was found to be more prevalent in dengue fever without warning signs, while the honeycomb pattern was found to be more prevalent in severe dengue fever" [1]. Indeed, the gall bladder problem in dengue is possible but is rarely mentioned. The investigation of abnormality of the hepatobiliary tract usually yields positive findings and confirms the problem in dengue patients [2]. Nevertheless, the confounding factors that might lead to the change in gall bladder are possible and this has to be carefully considered. In tropical areas in which dengue fever is endemic, there are several tropical infections including hepatitis and hepatobiliary parasitosis that might lead to an abnormal gall bladder. Some abnormal gall bladder patterns, such as thickening, might be unlikely to occur in the short period of acute febrile illness of dengue.

\section{Conflict of Interest}

The authors declare that they have no conflict of interest.

\section{References}

[1] Parmar JP, Mohan C, Vora M. Patterns of Gall Bladder Wall Thickening in Dengue Fever: A Mirror of the Severity of Disease. Ultrasound Int Open 2017; 3: E76-E81

[2] Wiwanitkit V. Dengue fever: diagnosis and treatment. Expert Rev Anti Infect Ther 2010; 8: 841-845 